\title{
Analisis Video Following To Followers Ratio Tiktok Pada 5 Brand Kendaraan Termahal
}

\author{
I Kadek Raditya Suta \\ radityasuta918@gmail.com
}

\begin{abstract}
TikTok is a social media application launched by a Chinese company. TikTok allows users to create 15-second videos accompanied by music, filters, and several other creative features. In Indonesia, there are 30.7 million active users, making Indonesia the country with the largest TikTok users in the world. The large number of active TikTok users in Indonesia can certainly provide an opportunity for brands to make the TikTok platform a social media marketing platform. The 5 most expensive vehicle brands that use TikTok as a marketing platform are: Hondaisme, YamahaIndonesia, Suzuki_id, Hyundaimotorindonesia, Mitsubishimotorsid. The purpose of this study is to calculate the credibility of the TikTok 5 Most Expensive Vehicle Brand account performance. The method used for this research is quantitative exploratory method. The results of this study indicate that the most expensive vehicle gets the first rank and has good account performance credibility.
\end{abstract}

\begin{abstract}
ABSTRAK
TikTok merupakan aplikasi sosial media yang diluncurkan oleh perusahaan asal Tiongkok. TikTok memungkinkan penggunanya membuat video berdurasi 15 detik yang disertai dengan musik, filter, dan beberapa fitur kreatif lainnya. Di Indonesia terdapat 30,7 juta pengguna yang aktif sehingga menjadikan Indonesia sebagai negara dengan pengguna TikTok terbesar di dunia. Maraknya jumlah pengguna TikTok yang aktif di Indonesia tentu dapat memberikan peluang bagi brand untuk menjadikan platform TikTok sebagai platform social media marketing. Adapun 5 Brand kendaraan termahal yang memanfaatkan TikTok sebagai platform marketing, yaitu : Hondaisme, Yamahaindonesia, Suzuki_id, Hyundaimotorindonesia, Mitsubishimotorsid. Tujuan dari penelitian ini yaitu untuk menghitung kredibilitas dari performa akun TikTok 5 Brand Kendaraan Termahal. Metode yang digunakan untuk penelitian ini yaitu metode eksploratif kuantitatif. Hasil dari penelitian ini menunjukan bahwa kendaraan termahal mendapatkan peringkat pertama dan memiliki kredibilitas performa akun yang baik.
\end{abstract}

Keyword : Credibility Account TikTok ; Social Media Marketing ; Social Media TikTok ; Following to Followers Ratio ; Kendaraan Termahal di Indonesia. 


\section{PENDAHULUAN}

Seiring dengan kemajuan tekhnologi, maka banyaknya media yang dapat digunakan manusia untuk dijadikan alat dalam berkomunikasi, demikian pula dengan media sosial yang dapat dengan mudah diakses melalui jaringan internet. Pada umumnya fungsi dari media sosial diantaranya untuk berbagi pesan dengan banyak pengguna media sosial itu sendiri,yaitu berupa berita (informasi), gambar (foto) dan juga tautan video. Media sosial tidak hanya dapat di akses di perangkat komputer, tetapi dengan adanya aplikasi di smartphone atau telepon pintar, maka semakin memudahkan masyarakat untuk mengakses media sosial secara mobile sehingga dapat diakses kapanpun dan di manapun.(Susilowati 2018). Pada journal (Ruth and Candraningrum 2020) menjelaskan menurut Sensor Tower, sebuah lembaga penyedia survei mengenai aplikasi ekonomi global asal Amerika Serikat, Tiktok berhasil menjadi aplikasi nomor 1 yang paling banyak diunduh pada tahun 2019 sebanyak 1 milliar kali di App Store dan Google Play dan berhasil meraih kepopuleran tertinggi di 6 negara dan salah satunya adalah Indonesia.

Perkembangan teknologi media sosial memberikan dampak yang signifikan terhadap proses komunikasi. Proses komunikasi yang awalnya hanya dengan media email dan chatting kini sudah dikembangkan dengan tersedianya jejaring media sosial yang mendukung proses komunikasi. Contoh aplikasi media sosial yang memiliki fitur untuk komunikasi serta banyak pengguna yaitu aplikasi Instagram. Instagram merupakan aplikasi berbagi foto yang memungkinkan pengguna mengambil foto, menerapkan filter digital, dan membagikannya ke berbagai layanan jejaring sosial. (Prihatiningsih 2017).

Di Indonesia, terdapat 30,7 juta pengguna TikTok yang aktif sehingga menjadikan Indonesia sebagai negara dengan pengguna TikTok terbesar di dunia. Maraknya jumlah pengguna TikTok aktif di Indonesia tentu dapat memberikan peluang bagi brand untuk menjadikan platform ini sebagai platform social media marketing. Cukup banyak akun perusahaan-perusahaan terkenal yang ada pada tiktok, contohnya seperti 5 Brand Kendaraan Termahal antara lain : Hondaisme, Yamahaindonesia, Suzuki_id, Hyundaimotorindonesia, Mitsubishimotorsid. (Patriawan, Putra, and Setyono 2021)

Penelitian ini menggunakan metode eksploratif kuantitatif, dan akan menghitung menggunakan rasio-rasio yang ada pada TikTok. Penelitian ini hanya berfokus untuk menghitung kredibilitas Video Following to Followers Ratio 5 Brand Kendaraan Termahal. Tujuan dari penelitian ini adalah mengetahui kredibilitas performa dari akun TikTok 5 Brand Kendaraan Termahal, menggunakan Video Following to Followers Ratio.

\section{TINJAUAN PUSTAKA}

Adanya media sosial, hanya butuh hitungan detik untuk menyampaikan pesan kepada seseorang yang ingin dituju. Media sosial merupakan alat dimana kita bisa menulis pesan, merekam video dan mengirimnya secara personal maupun diunggah secara publik dan penerima atau publik pun bisa menerimanya dengan cepat dalam hitungan detik saja. Media sosial bisa mempertemukan orang dari berbeda negara, komunikasi yang dilakukan tanpa perlu bertemu secara langsung, mempertemukan para alumni sekolah yang sudah berpisah 
kota, sampai meminta 3 bantuan pada publik untuk menemukan orang yang tidak pernah dijumpai lagi.

Salah satu media sosial yang sedang ramai digunakan oleh hampir kebanyakan orang saat ini adalah TikTok. Media Sosial TikTok dengan mudah diakses oleh hampir kebanyakan kaum milenial, hanya dengan mengunduh dan membuat akun, mereka sudah bisa memiliki akun di TikTok. Di tengah perkembangan jaman yang sudah modern ini, media sosial sepertinya telah menjadi kebutuhan primer di masyarakat, berdampingan dengan kebutuhan pokok seperti makan dan bekerja maupun belajar.(Hasiholan, Pratami, and Wahid 2020)

Media social tik tok ini merupakan media social yang memberikan efek special yang unik dan menarik yang bisa digunakan oleh para pengguna nya. Media social ini dapat membuat pengguna (peserta didik) merasa senang, karena video-video yang mereka buat dengan berbagai music. Dengan menggunakan media tersebut setiap penggunanya pun tidak bisa hanya sekali dua kali karena begitu senang nya mereka menggunakan media social tik tok. (Marini 2019)

Aplikasi tiktok dibuat untuk menghibur pengguna lainnya. Peneliti (Bulele and Wibowo 2020) menyatakan cara untuk mendapatkan aplikasi tersebut sangatlah mudah, mereka bisa mengunduh aplikasi tersebut melalui aplikasi smarthphone playstore atau dari google.

Pada aplikasi Tik Tok, penggunanya dapat membuat video yang berdurasi 15 detik dan 60 detik serta bisa memberikan special effects dan music yang unik dan beragam sehingga penggunanya bias menggunakan fitur-fitur tersebut dengan membuat gaya tarian sendiri sesuai dengan musiknya, hal itu mendorong penggunanya untuk menjadi seorang content creator. Musik-musik yang tersedia juga merupakan musik dari artis terkenal, banyak juga music yang tadinya tidak terkenal menjadi terkenal karena dipakai sebagai background music di video-video yang di unggah di Tik Tok. Video-video yang dibuat oleh penggunanya juga bisa dibagikan lagi ke aplikasi lain seperti Instagram (“Tiktok” 2020).

\section{METODE PENELITIAN}

Penelitian ini menggunakan metode eksploratif kuantitatif untuk mengetahui kredibilitas dari performa akun tiktok pada 5 kendaraan termahal. Metode Eksploratif merupakan penelitian yang bertujuan untuk menggali secara luas tentang sebab-sebab atau hal-hal yang mempengaruhi terjadinya sesuatu dan dipakai manakala kita belum mengetahui (Nurlailiyah 2016). Ada beberapa langkah yang harus dilakukan dalam penelitian ini, sehingga mampu menemukan peringkat pertama akun Tiktok Vendor 5 Kendaraan Termahal yang memiliki perfoma terbaik. Langkah-langkah yang dilakukan pada penelitian ini, diantaranya yaitu :

\section{Melakukan Eksplorasi Pada Website Untuk Menentukan Objek yang Akan Dianalisa.}

Eksplorasi ini dilakukan pada beberapa halaman website yang menyediakan informasi mengenai objek yang akan di teliti. Eksplorasi ini dilakukan untuk menemukan nama- 
nama vendor kendaraan termahal yang akan dijadikan objek analisa. Setelah melakukan eksplorasi pada halaman website, maka langkah selanjutnya yaitu mencari nama akun Tiktok dari masing-masing vendor kendaraan. Selanjutnya memastikan semua vendor memiliki akun pada aplikasi sosial media Tiktok.

\section{Menghitung Nilai Rata-Rata Variable Dari Top 5 Vendor Kendaraan Termahal.}

Pada langkah ini, peneliti menghitung nilai variable Following dan variable Follower. Variabel merupakan setiap jumlah, kuantitas ,karakteristik, atau yang dapat di dihitung. atau diukur (Hidayat 2012) Untuk menghitung nilai rata-rata dari variabel Following dan variabel Follower yaitu dengan cara mengambil jumlah following serta follower masing-masing akun Tiktok 5 Kendaraan Termahal kemudian di hitung sehingga menemukan nilai rata-rata dari masing-masing variable.

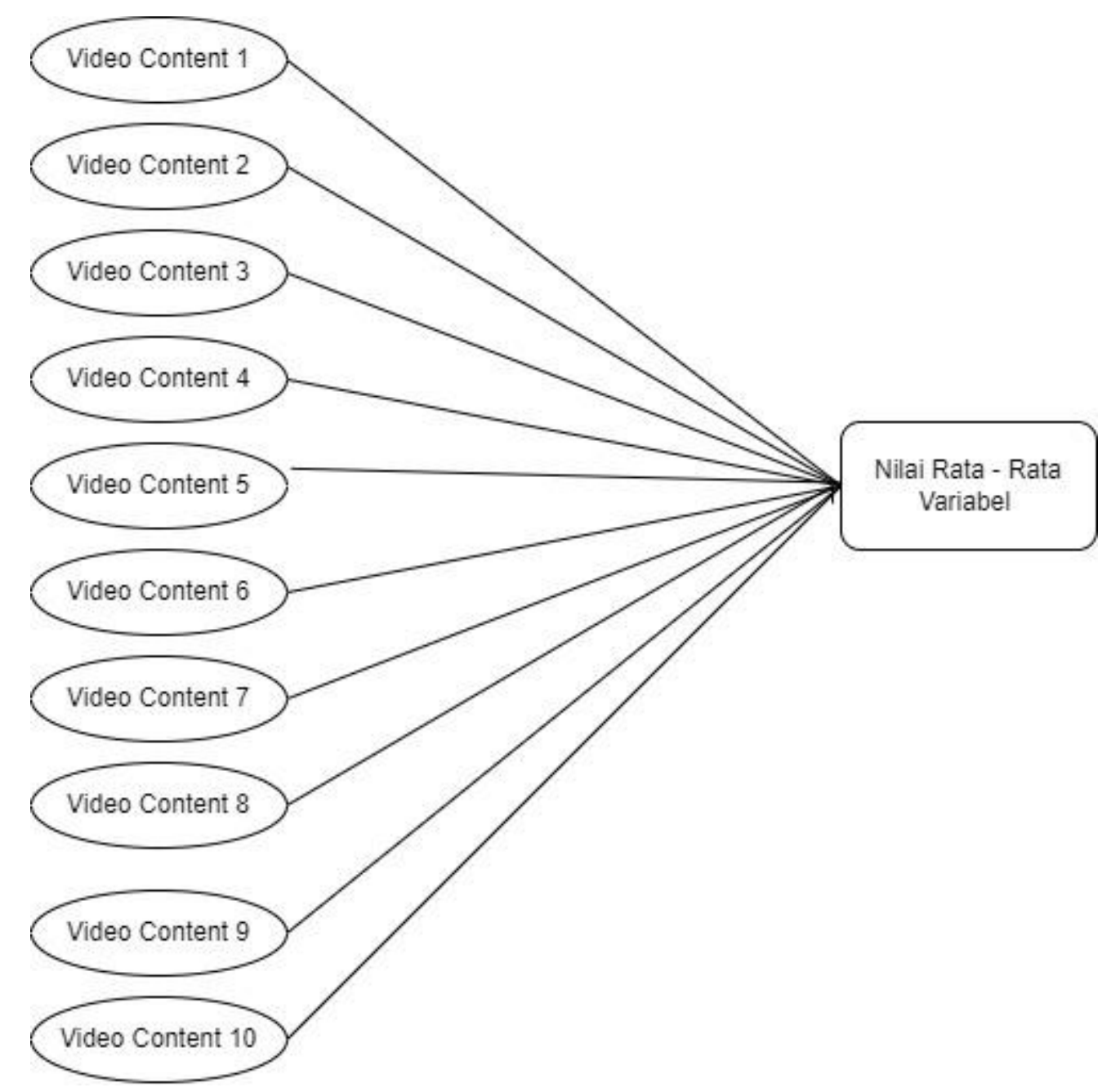

Gambar 1. Analisa Nilai Rata - Rata Variabel

\section{Menghitung Nilai Kredibilitas Rasio}

Untuk menghitung nilai kredibilitas dari Following to Follower Rasio, peneliti menggunakan cara dengan membagi nilai variabel pertama dengan nilai variabel kedua. Jika Following memiliki nilai 100 dan Follower memiliki nilai 300, maka cara 
menghitungnya yaitu $100: 300=0,3$. Dengan begitu nilai dari Following to Follower ratio adalah 0,3 .

\section{Menentukan Peringkat Pada Akun Tiktok}

Langkah terakhir pada penelitian ini adalah menentukan peringkat pada masing-masing rasio yang sudah dianalisis sebelumnya. Pada saat penentuan peringkat perlu melihat karakteristik dari rasio yang diteliti. Jika karakteristik rasio dikatagorikan rendah, maka objek yang memiliki nilai terendah akan mendapatkan angka 5 dan objek yang memiliki nilai tertinggi akan mendapatkan angka 1 . Namun jika rasio memiliki kategori tinggi maka objek yang mendapatkan nilai tinggi akan mendapatkan angka 5 dan objek yang mendapatkan nilai terendah akan mendapatkan angka 1. Setelah mendapatkan hasil kredibilitas ratio maka dapat disimpulkan objek yang mana mendapatkan peringkat 1 sampai dengan peringkat 5 .

\section{HASIL DAN PEMBAHASAN}

Akun TikTok 5 Kendaraan Termahal, diantaranya :

1. Hondaisme

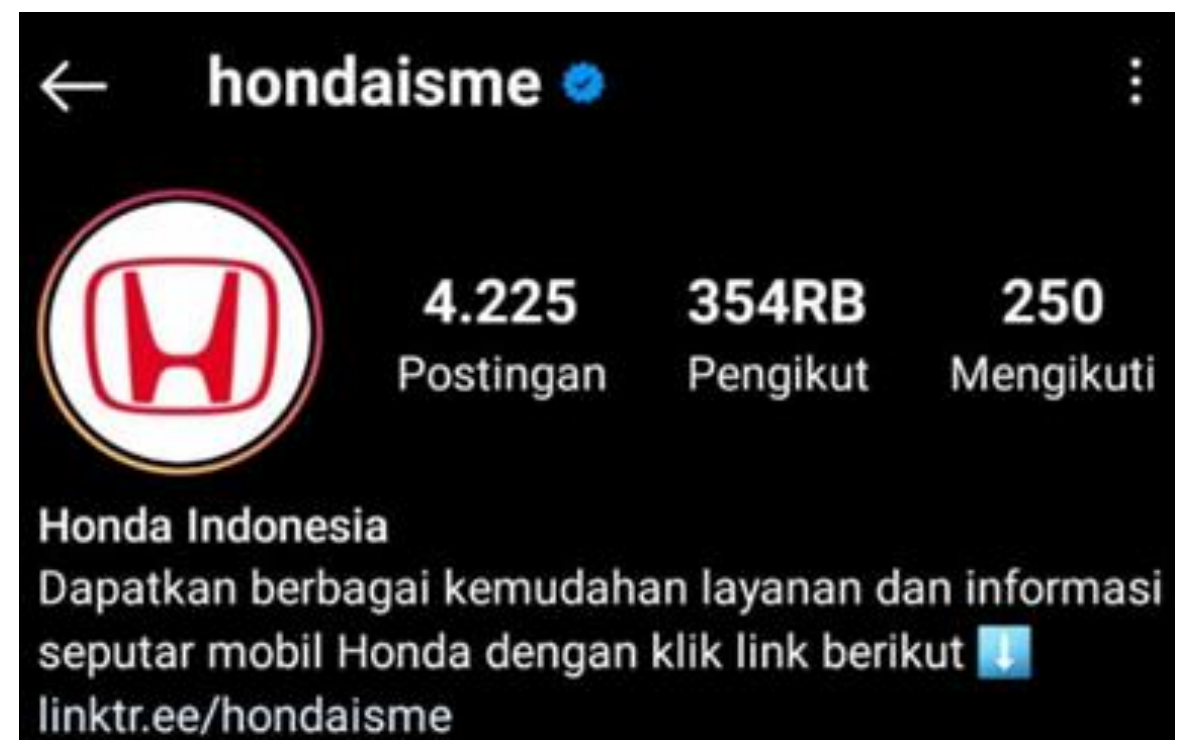

Gambar 2. Akun TikTok Hondaisme

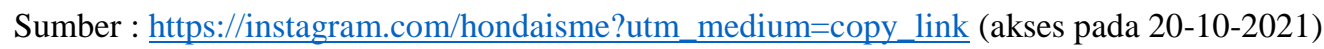


2. Yamaha

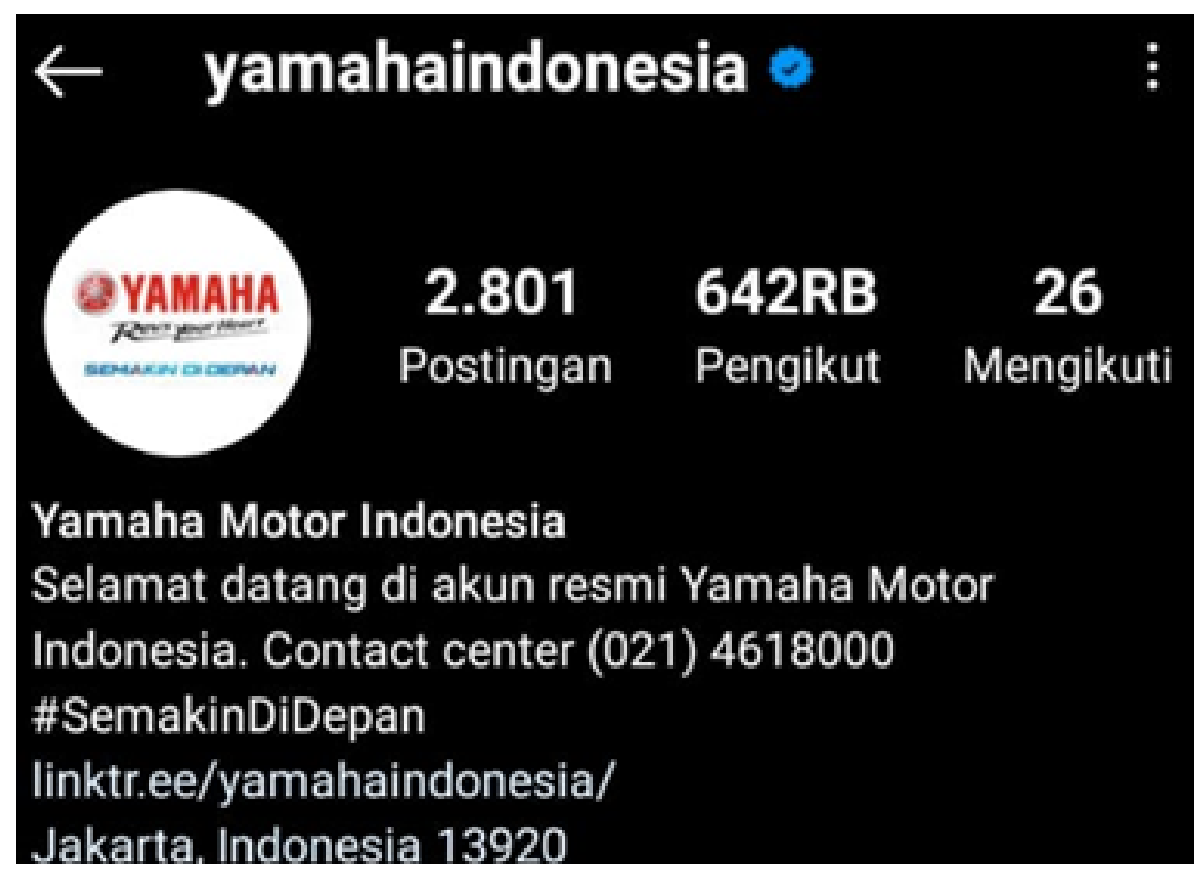

Gambar 3. Akun TikTok Yamaha

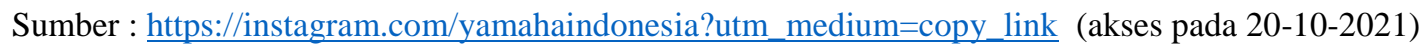

3. Suzuki

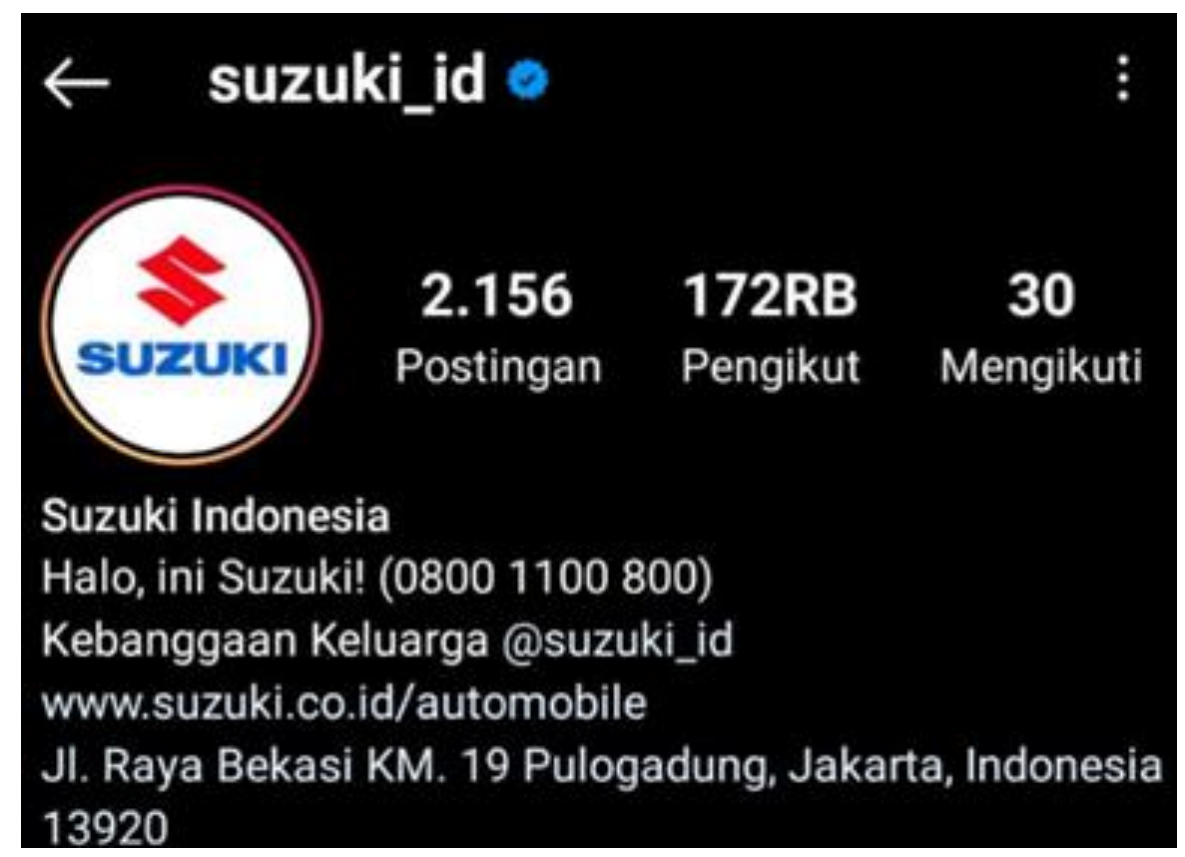

Gambar 4. Akun TikTok Suzuki

Sumber : https://instagram.com/suzuki_id?utm_medium=copy_link (akses pada 20-10-2021) 
4. Hyundai

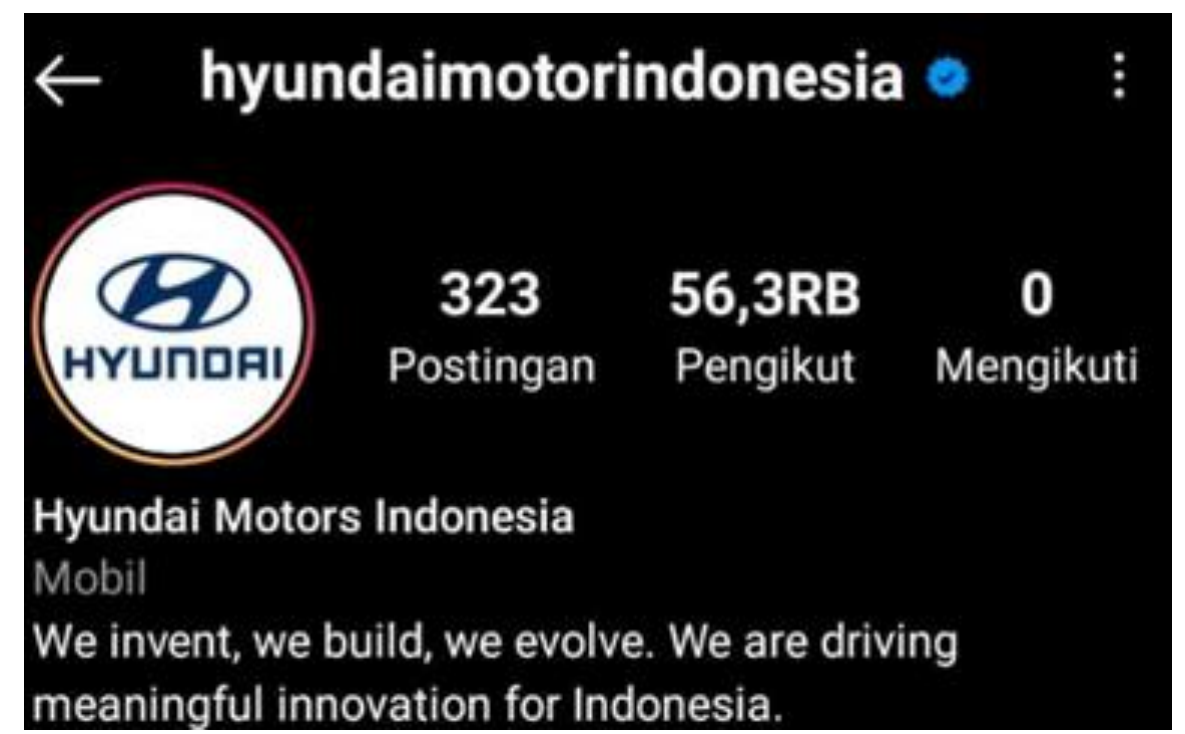

Gambar 5. Akun TikTok Hyundai

Sumber : https://instagram.com/hyundaimotorindonesia?utm_medium=copy_link akses pada 20-10-2021)

5. Mitsubishi

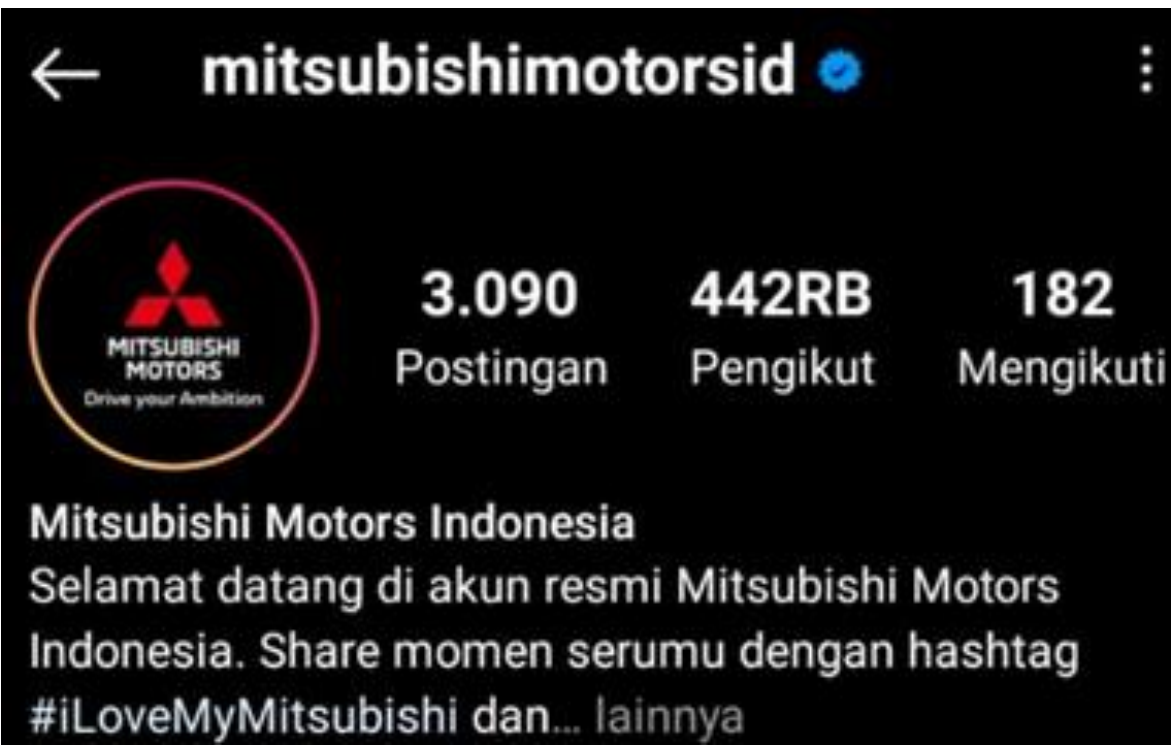

Gambar 6. Akun TikTok Mitsubishi

Sumber : https://instagram.com/mitsubishimotorsid?utm_medium=copy_link akses pada 20-10-2021) 
Dari ketujuh akun TikTok 5 kendaraan terbaik, peneliti menemukan nilai dari masing-masing variabel yang ada untuk menghitung rasio Following to Followers dari setiap akun. Pada akun TikTok terdapat 7 variabel, diantaranya yaitu :

1. Likes

2. Followers

3. Following

4. Video Likes

5. Video Comments

6. Video Share

7. Video View

Dari variabel tersebut peneliti hanya fokus untuk menemukan hasil dari 2 variabel, yaitu :

\section{Following}

2. Followers

Dari variabel tersebut kemudian dianalisa sehingga menemukan nilai rata-rata Following to Followers rasio yaitu dengan cara mengambil minimal 5 produk kemudian di hitung sehingga menemukan nilai rata-rata dari masing-masing variabel. Berikut merupakan tabel nilai rata-rata dari masing-masing Brand :

Tabel 1. Analisa Nilai Rata-Rata Nilai Variabel Video Following to Followers Akun TikTok Honda

\begin{tabular}{|c|c|c|}
\hline \multicolumn{2}{|c|}{ HONDA } \\
\hline NO & FOLLOWING & FOLLOWERS \\
\hline 1 & 121 & 690 \\
\hline 2 & 96 & 2,233 \\
\hline 3 & 62 & 5,353 \\
\hline 4 & 131 & 6,643 \\
\hline 5 & 4466 & 6,887 \\
\hline 6 & 47 & 5,555 \\
\hline 7 & 52 & 3,445 \\
\hline 8 & 45 & 5,566 \\
\hline 9 & 76 & 3,900 \\
\hline 10 & 139 & 3,433 \\
\hline TOTAL & $\mathbf{5 2 3 . 5}$ & $\mathbf{4 3 7 0 . 5}$ \\
\hline
\end{tabular}


Tabel 2. Analisa Nilai Rata-Rata Nilai Variabel Video Following to Followers Akun TikTok Yamaha

\begin{tabular}{|c|c|c|}
\hline \multicolumn{4}{|c|}{ YAMAHA } \\
\hline NO & FOLLOWING & FOLLOWERS \\
\hline 1 & 5 & 33 \\
\hline 2 & 96 & 34 \\
\hline 3 & 62 & 344 \\
\hline 4 & 555 & 5 \\
\hline 5 & 678 & 455 \\
\hline 6 & 543 & 6 \\
\hline 7 & 668 & 455 \\
\hline 8 & 45 & 3 \\
\hline 9 & 54 & 4 \\
\hline 10 & 88 & 6,554 \\
\hline TOTAL & $\mathbf{2 7 9 . 4}$ & $\mathbf{7 8 9 . 3}$ \\
\hline
\end{tabular}

Sumber : Pengolah Data Excel

Tabel 3. Analisa Nilai Rata-Rata Nilai Variabel Video Following to Followers Akun TikTok Suzuki

\begin{tabular}{|c|c|c|}
\hline \multicolumn{2}{|c|}{ SUZUKI } \\
\hline NO & FOLLOWING & FOLLOWERS \\
\hline 1 & 5556 & 122 \\
\hline 2 & 7774 & 344 \\
\hline 3 & 553 & 556 \\
\hline 4 & 77 & 324 \\
\hline 5 & 55 & 566 \\
\hline 6 & 77 & 886 \\
\hline 7 & 5555 & 777 \\
\hline 8 & 77 & 889 \\
\hline 9 & 7 & 190 \\
\hline 10 & 139 & 155 \\
\hline TOTAL & $\mathbf{1 9 8 . 7}$ & $\mathbf{4 8 0 . 9}$ \\
\hline
\end{tabular}

Sumber : Pengolah Data Excel 
Tabel 4. Analisa Nilai Rata-Rata Nilai Variabel Video Following to Followers Akun TikTok Mitsubhisi

\begin{tabular}{|c|c|c|}
\hline \multicolumn{3}{|c|}{ MITSUBISHI } \\
\hline NO & FOLLOWING & FOLLOWERS \\
\hline 1 & 899 & 654 \\
\hline 2 & 96 & 654 \\
\hline 3 & 554 & 566 \\
\hline 4 & 667 & 564 \\
\hline 5 & 654 & 66 \\
\hline 6 & 47 & 6,785 \\
\hline 7 & 443 & 8,856 \\
\hline 8 & 447 & 5,566 \\
\hline 9 & 9900 & 455 \\
\hline 10 & 139 & 7,000 \\
\hline TOTAL & $\mathbf{1 3 8 4 . 6}$ & $\mathbf{3 1 1 6 . 6}$ \\
\hline
\end{tabular}

Sumber : Pengolah Data Excel

Tabel 5. Analisa Nilai Rata-Rata Nilai Variabel Video Following to Followers Akun TikTok Hyundai

\begin{tabular}{|c|c|c|}
\hline \multicolumn{2}{|c|}{ HYUNDAI } \\
\hline NO & FOLLOWING & FOLLOWERS \\
\hline 1 & 9009 & 12000 \\
\hline 2 & 12300 & 150,000 \\
\hline 3 & 62 & 66 \\
\hline 4 & 131 & 544 \\
\hline 5 & 56 & 46 \\
\hline 6 & 47 & 556 \\
\hline 7 & 52 & 33 \\
\hline 8 & 45 & 445 \\
\hline 9 & 76 & 888 \\
\hline 10 & 139 & 699 \\
\hline TOTAL & $\mathbf{2 1 9 1 . 7}$ & $\mathbf{1 6 5 2 7 . 7}$ \\
\hline
\end{tabular}

Sumber : Pengolah Data Excel 
Setelah menghitung nilai rata - rata tersebut, maka akan menemukan hasil akhir nilai rata rata dari variabel Following dan variabel Followers rasio.

Tabel 6. Nilai Variable Pada Akun 5 Brand Kendaraan Termahal.

\begin{tabular}{|c|c|c|c|c|c|}
\hline Variable & Honda & Yamaha & suzuki & Misthubhisi & hyundai \\
\hline following & 523.5 & 274.9 & 198.7 & 1384.6 & 2191.7 \\
\hline followers & 4370.5 & 789.3 & 480.9 & 3116.6 & 16527.7 \\
\hline
\end{tabular}

Sumber : Pengolah Data Excel

Pada akun TikTok terdapat 17 rasio yang relevan digunakan untuk mengukur kredibilitas pada masing - masing akun. Namun pada penelitian kali ini hanya berfokus untuk menghitung Following To Followers. Untuk menghitung kredibilitas dari masing - masing akun TikTok setiap Kendaraan, peneliti menghitung dengan cara : variabel 1 dibagi dengan variabel 2, sehingga ditemukan hasil analisa dari rasio tersebut.

Tabel 7. Hasil Perhitungan Rasio Akun TikTok

\begin{tabular}{|c|c|c|c|c|c|}
\hline RATIO & Honda & Yamaha & Suzuki & Mitsubishi & Hyundai \\
\hline $\begin{array}{c}\text { Video } \\
\text { following to } \\
\text { follower ratio }\end{array}$ & 0.516241436 & 0.035398454 & 0.413183614 & 0.044426619 & 0.013260768 \\
\hline
\end{tabular}

Sumber : Pengolah Data Excel

Following To Followers Ratio memiliki karakteristik yang tinggi, artinya semakin tinggi nilai yang dihasilkan maka semakin baik kredibilitas dari perfoma akun tersebut. Untuk memberikan peringkat pada masing - masing Kendaraan, Peneliti memberikan angka 7 kepada vendor yang mendapatkan nilai tertinggi dan angka 1 untuk vendor kendaraan yang mendapatkan nilai terendah. Berikut merupakan table urutan nilai yang dihasilkan oleh masing - masing Kendaraan.

Tabel 8. Nilai Rasio Akun Tiktok 5 Brand Kendaraan Termahal

\begin{tabular}{|c|c|c|c|c|c|}
\hline \multirow[b]{2}{*}{ RATIO } & \multicolumn{5}{|c|}{ Nilai } \\
\hline & Honda & Yamaha & Suzuki & Mitsubishi & Hyundai \\
\hline $\begin{array}{l}\text { Video } \\
\text { following to } \\
\text { follower ratio }\end{array}$ & 5 & 2 & 3 & 4 & 1 \\
\hline
\end{tabular}


Dari Tabel Nilai Rasio Akun TikTok 5 Brand Kendaraan Termahal dapat disimpulkan bahwa Kendaraan Honda mendapatkan nilai tertinggi untuk rasio Following to Followers. Sedangkan akun Tiktok Hyundai mendapatkan nilai terendah untuk rasio ini. Jadi, pada penelitian ini Kendaraan Honda memilki kredibilitas perfoma yang lebih baik dibandingkan dengan Kendaraan yang lainnya.

\section{KESIMPULAN}

Tujuan dari penelitian ini adalah mengetahui kredibilitas perfoma dari akun TikTok 5 Brand Kendaraan Termahal menggunakan Following To Followers Ratio. 5 Brand Kendaraan Termahal diantaranya: Honda, Yamaha, Suzuki, Mitsubishi, Hyundai. Dari Kelima Brand tersebut dapat disimpulkan bahwa :

1. Peringkat pertama diraih oleh Brand Kendaraan Honda dengan nilai yaitu : 0.516241436

2. Peringkat kedua diraih oleh Brand Kendaraan Mitsubishi dengan nilai yaitu : 0.044426619

3. Peringkat ketiga diraih oleh Brand Kendaraan Suzuki dengan nilai yaitu : 0.413183614

4. Peringkat keempat diraih oleh Brand Kendaraan Yamaha dengan nilai yaitu : 0.035398454

5. Peringkat kelima diraih oleh Brand Kendaraan Hyundai dengan nilai yaitu : 0.013260768 


\section{DAFTAR PUSTAKA}

Bulele, Yohana Noni, and Tony Wibowo. 2020. "Analisis Fenomena Sosial Media Dan Kaum Milenial: Studi Kasus Tiktok." Conference on Business, Social Sciences and Innovation Technology 1 (1): 565-72. http://journal.uib.ac.id/index.php/cbssit.

Hasiholan, Togi Prima, Rezki Pratami, and Umaimah Wahid. 2020. "Pemanfaatan Media Sosial Tik Tok Sebagai Media Kampanye Gerakan Cuci Tangan Di Indonesia Untuk Mencegah Covid-19." Communiverse : Jurnal Ilmu Komunikasi 5 (2): 70-80. https://doi.org/10.36341/cmv.v5i2.1278.

Hidayat, Anwar. 2012. "Variabel Penelitian Adalah: Pengertian, Jenis, Contoh." Statistikian.Com. 2012.

Marini, Riska. 2019. Pengaruh Media Sosial Tik Tok Terhadap Prestasi Belajar Peserta Didik Di SMPN 1 Gunung Sugih Lab. Lampung Tengah.

Nurlailiyah, Siti. 2016. "Studi Dampak Facebook Terhadap Perubahan Pola Komunikasi Antar Pribadi Mahasiswa IAIN Jember."

Patriawan, Desmas Arifianto, Janu Hadi Putra, and Bambang Setyono. 2021. "Analisis Perbandingan Biaya Operasional Antara Kendaraan Listrik , Bensin Dan Diesel Institut Teknolgi Adhi Tama Surabaya , Fakultas Teknologi Industri ,." Seminar Nasional Teknologi Industri Berkelanjutan I, 128-35. https://ejurnal.itats.ac.id/senastitan/article/viewFile/1681/1444.

Prihatiningsih, Witanti. 2017. "Motif Penggunaan Media Sosial Instagram Di Kalangan Remaja." Communication 8 (1): 51. https://doi.org/10.36080/comm.v8i1.651.

Ruth, Debra, and Diah Ayu Candraningrum. 2020. "Pengaruh Motif Penggunaan Media Baru Tiktok Terhadap Personal Branding Generasi Milenial Di Instagram.” Koneksi 4 (2): 207. https://doi.org/10.24912/kn.v4i2.8093.

Susilowati. 2018. "Pemanfaatan Aplikasi Tiktok Sebagai Personal Branding Di Instagram." Jurnal Komunikasi 9 (2): 176-85.

“Tiktok." 2020, 1-10. 